\title{
Steatitis in a Wild Common Loon (Gavia immer) and Review of the Literature
}

\author{
Jessica Bridgers, BS, Sara Hall, MS, DVM, Yuri Lawrence, MS, DVM, \\ Tara RitTle, DVM, Rebecca Harris, PhD, Mark Pokras, DVM \\ WILDLIFE ClINIC \\ Tufts University Cummings School of Veterinary Medicine \\ North Grafton, Massachusetts
}

\begin{abstract}
Steatitis was diagnosed at necropsy in a debilitated, adult female common loon (Gavia immer), constituting the first known case of the disease in loons. Steatitis has been described most commonly in a variety of domestic and captive species. In these cases, the cause of steatitis is most often vitamin E deficiency in a diet comprised mainly of fish. Until roughly 20 years ago, the occurrence of steatitis in wildlife was relatively rare. However, the condition is being seen increasingly in herons in Japan and both coasts of the US. While several environmental factors have been correlated with the outbreaks, the causes remain unclear and may be mul tifactorial. Rehabilitators are in a unique position to recognize and report the event of steatitis in wild birds such as loons, allowing researchers to better understand the extent and cause of steatitis in wild birds.
\end{abstract}

Key words: steatitis, fat, common loon, Gavia immer, vitamin E

Jessica Smith Bridgers received her BS in Biology from the University of New Mexico and is currently a research assistant for Dr. Pokras at the Tufts Wildlife Clinic.

Sara Hall obtained a BS in marine biology and an MS in zoology prior to getting her DVM at Tufts. She finished an internship in small animal medicine and surgery and currently works as an emergency veterinarian in Tucson, $A Z$.

Yuri Lawrence received his DVM at Tufts and is currently a Small Animal Internal Medicine Resident and PhD student at Oregon State University.

Tara Rittle graduated from the University of Florida, College of Veterinary Medicine in 2003 and completed an internship in Wildlife and Conservation Medicine at Tufts University in 2004. She is currently working as a small animal and exotics veterinarian in Atlanta, GA.

Becky Harris is former director of the Massachusetts Audubon Coastal Waterbird Program and is an adjunct professor at Tufts University and Brandeis University. She is co-founder of the Seabird Ecological Assessment Network (SEANET), a collaborative citizen science program of Tufts Cummings School of Veterinary Medicine that focuses on using seabirds as sentinels of environmental health.

Mark Pokras is a wildlife veterinarian, former director of the Tufts Wildlife Clinic, and one of the founders of Tufts' Center for Conservation Medicine. He has been involved in wildlife rehabilitation since 1971.

\section{CAse PREsentation}

In June of 2004, an adult female common loon (Gavia immer) was retrieved from Togus Pond in Augusta, Maine and brought to Avian Haven, a wild bird rehabilitation center. The loon was observed to be quiet, weak, lethargic, thin, and unconcerned with human presence. The loon died a short time later and was shipped to Tufts Cummings School of Veterinary Medicine as a part of an ongoing regional mortality study. The body was weighed, radiographed, and a necropsy was performed. The bird was thin (2182 g, normal weight 3380-4650 g, Dunning 2008). Radiographs revealed no significant findings. At necropsy there were good fat stores throughout the body, including abdominal fat and coronary fat; however, the general muscle condition was poor. The subcutaneous fat in the abdominal area was hardened and yellow-brown, while all other fat within the body appeared normal. The gastrointestinal tract was distended with gas and a small portion of the right liver lobe appeared necrotic. Numerous fungal plaques were noted on the outside of the trachea, major vessels, pericardium, within the lungs, and on airsac walls. These plaques appeared cream colored with a gray/ green center, suggesting infection with Aspergillus sp.

Tissues from the necropsy were sent for histological examination (Northwest Zoopath, Monroe, WA) and a diagnosis of severe necrotizing steatitis with intralesional bacteria was made. Adipose tissue was found with severe, multifocal to coalescing, granulomatous or heterophilic inflammation and necrosis was associated with large numbers of extracellular and intracellular bacteria. Based on previous incidences of steatitis involving cyanobacteria (blue-green bacteria) producing the toxin microcystin, samples from the loon were tested for the presence of microcystin and were found to be negative. Water from Togus Pond and neighboring regions was not tested. 


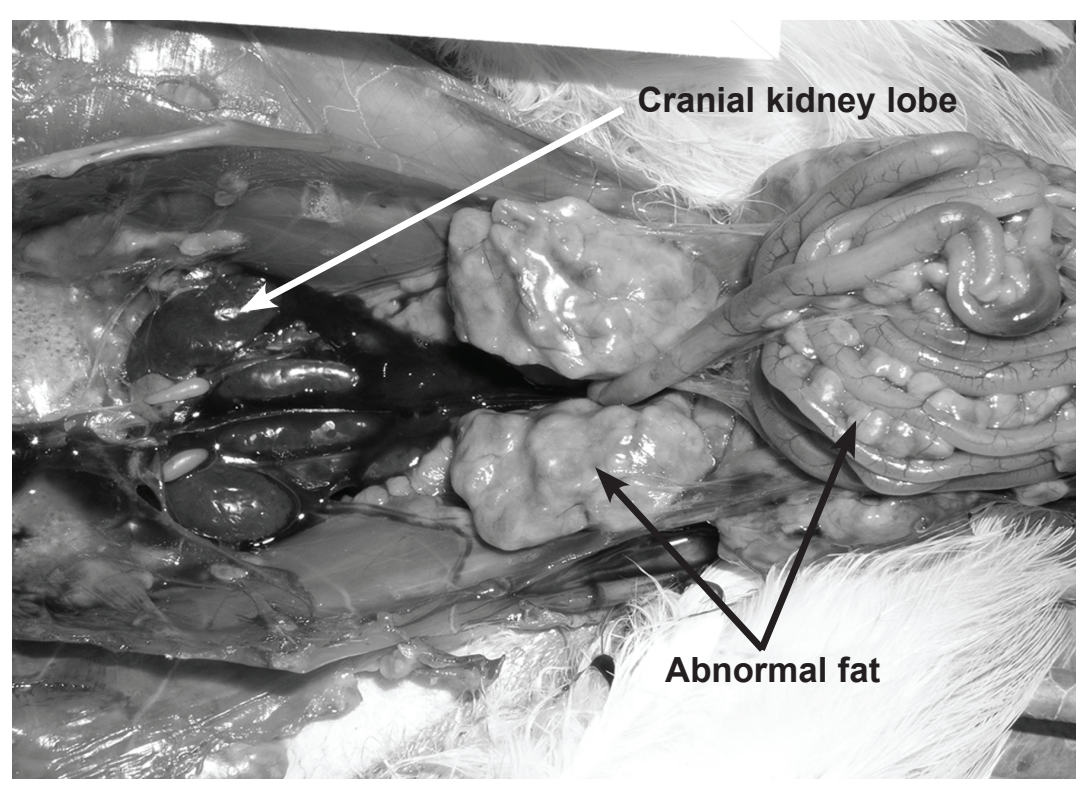

Figure 1. Necropsied common loon (Gavia immer) showing abnormal subcutaneous fat deposits in the abdominal cavity.

This is the first known case of steatitis reported in a common loon. The diet of the loon prior to its death is unknown. As adults, loons occupy freshwater environments during the breeding season and marine environments during the non-breeding season, and are primarily fish eaters. However, they will eat what they can see easily and capture readily, including invertebrates and some plant material.

\section{REVIEW}

Steatitis is an inflammatory disease of adipose tissue (fat) with accompanying deposition of ceroid pigment (a form of oxidized fats) within the cells (Kahn 2005; Niza et al 2003). This condition results from excessive lipid peroxidation and has been described previously in cats (Niza et al 2003), mustelids (Brooks et al 1985), equids (Menzies-Gow et al 2002), swine (Kirby 1981), primates (Juan-Salles et al 2003), kangaroos (Kabak et al 2011), fish (Begg et al 2000; Huchzermeyer et al 2011), reptiles (Ladds et al 1995), crocodiles (Huchzermeyer et al 2011), and birds (Pollock et al 1999; Wong et al 1999; Neagari et al 2011). In the western United States (US), steatitis was first recorded in wild great blue herons (Ardea herodias) over 20 years ago. Since then, an increasing number and frequency of cases have been seen in both this species and blackcrowned night herons (Nycticorax nycticorax), to the point that in the San Diego area it is difficult to find young great blue herons that do not manifest the syndrome (Dr. Judith St. Leger, SeaWorld of California, San Diego, CA, personal communication). In 2008, additional steatitis outbreaks in wild populations were reported in herons and egrets in a reservoir in Japan
(Neagari et al 2011), and in crocodiles and catfish in Kruger National Park, South Africa (Huchzermeyer et al 2011).

Symptoms of steatitis typically include fever, anorexia, depression, hyperesthesia (abnormal sensitivity to stimuli), reluctance to move, pain, and subcutaneous, irregular nodular masses (Koutinas et al 1993). Muscle degeneration also has been seen to occur in combination with nutritional steatitis (Brooks et al 1985) and affected birds have been found to present with the steatitis of several fat stores, weakness, lethargy, muscle atrophy, inability to fly, and aspergillosis infection.

Lipid peroxidation leading to steatitis can result from an imbalance between pro-oxidant compounds and antioxidant defenses, specifically the balance between the potent antioxidant vitamin $\mathrm{E}$ and polyunsaturated fatty acids (PUFAs). These fatty acids are particularly susceptible to peroxidation by free radicals and prooxidants (Webb and Twedt 2008; Niza et al 2003). The imbalance between vitamin $\mathrm{E}$ and PUFAs can be triggered by inadequate intake of vitamin $E$ in the diet, consumption of high levels of PUFAs that deplete vitamin $\mathrm{E}$, or a combination of the two (Niza et al 2003). Additionally, omega-3 fatty acids are more vulnerable to peroxidation than omega- 6 fatty acids (Surai et al 2001). PUFAs from marine fish are predominantly omega-3 fatty acids (Brooks et al 1985; Li et al 2011). Therefore, adequate consumption of vitamin $\mathrm{E}$ is invaluable to species that consume diets composed primarily of marine fish, as their requirements for the vitamin are higher (Dierenfield 1989, also personal communication 2012, Novus International, St. Louis, MO). Indeed, dietary steatitis has been induced in a number of captive species fed diets high in marine fish but deficient in vitamin $\mathrm{E}$ (Brooks et al 1985; Niza et al, 2003; Larsen et al 1983; Tocidlowski et al 1997; Manawatthana and Kasorndorkbua 2005).

Lipids are naturally occurring fats obtained in the diet and necessary for normal functions. Lipid peroxidation is a process whereby lipids that are part of cell membranes become chemically modified leading to cell and tissue damage. Polyunsaturated fats (PUFAs) are a type of lipid that is particularly susceptible to peroxidation. 


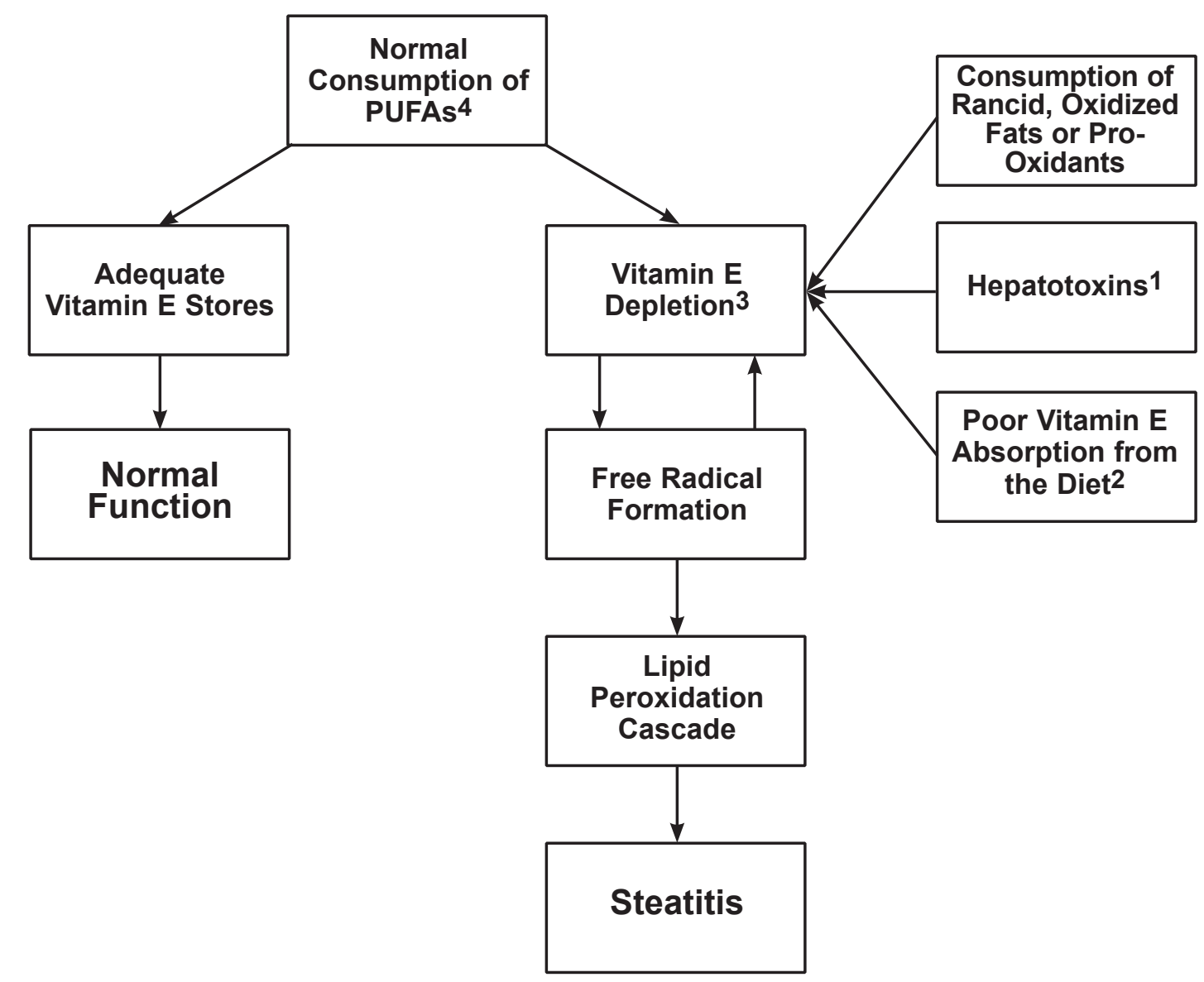

${ }_{1}^{1}$ Hepatotoxins can include compounds such as organic poisons (eg: microcystin), heavy metals, or certain drugs.

${ }^{2}$ Poor vitamin $E$ absorption can be caused by the absence of hepatic or biliary secretions, or any disorder that causes fat malabsorption.

${ }^{3}$ Other factors that contribute to vitamin $E$ depletion include the depletion of antioxidants (eg: vitamin $C$ or selenium), depletion of enzyme co-factors (eg: $\mathrm{Zn}, \mathrm{Cu}$ or $\mathrm{Mn}$ ), or excess heat.

${ }^{4}$ Balance of omega-3 to omega-6 ratio is also an important factor.

Thus, factors that prevent adequate consumption or absorption of vitamin $\mathrm{E}$ or any factor that depletes the body's vitamin E may lead to steatitis in species that regularly consume high levels of PUFAs. The presence of heavy metals can accelerate the peroxidation of PUFAs (Geraci and St. Aubin 1980; Van Vleet 1982) and anything toxic to the liver (hepatotoxins) can contribute to liver oxidative stress via a number of pathways (Jaeschke et al 2002; Jaeschke 2012). Vitamin $\mathrm{E}$ has been shown to decrease the effects of these hepatotoxins (Sokol et al 1998) and thus it is plausible that the presence of certain hepatotoxins also can lead to the depletion of vitamin $\mathrm{E}$.

Metabolism and excretion of vitamin E are important to its abundance and availability in the body (Traber 2005). Vitamin E is absorbed and delivered to the liver before being metabolized and excreted into the bile or urine (Traber 2005). Absorption requires biliary and pancreatic secretions and undergoes similar processes as those used to digest and metabolize fatty acids (Traber 2005). In the absence of pancreatic and/or biliary secretions, vitamin E absorption and secretion into the lymphatic system are poor or negligable (Traber 2005). Thus, any disorder that causes fat malabsorption or disrupts biliary and pancreatic secretions can lead to vitamin E deficiency (Traber 2005; Ohno et al 2003; Outas et al 2004; Potts et al 1975). Other factors that may increase the dietary requirements of vitamin E include increased vitamin A consumption, decreased consumption of other antioxidants or cofactors such as selenium, consumption of rancid (oxidized) fats, and high levels of pro-oxidants such as microcystin or aluminum (Klasing 2000; Brown 2011). 
The authors suggest two broad pathways that may place wild species (piscivorous populations in particular) at an increased risk for steatitis:

1. Ecological changes such as overfishing (Jennings and Kaiser 1998; Coll et al 2008) or climate change (Walther et al 2002) that alter marine trophic structure and may shift prey items to those with higher PUFA concentration than the predator species are capable of metabolizing and detoxifying, thus depleting the available vitamin E and leading to steatitis.

2. Environmental contaminants such as microcystin, heavy metals, or other pollutants may be depleting the animal's vitamin E or disrupting its absorption and metabolism, thus leaving the piscivore with little or no protection against lipid peroxidation in conjunction with their naturally highPUFA diet.

The presence of the cyanobacteria Microcystis in algal blooms has been linked to the development of steatitis, resulting in die-offs of great blue herons in the Chesapeake Bay, where in the fall of 2001 several great blue herons were diagnosed with steatitis (Rattner et al 2006). These birds presented with emaciation, lethargy, inability to fly, and an unusually hard abdomen. Concurrent to when the birds were diagnosed, nearby waters were found to contain large blooms of Microcystis, a cyanobacterium known to produce the hepatotoxin microcystin (MC). MC is known to cause oxidative stress to animal tissues including the liver (Campos and Vasconcelos 2010; Guzman and Solter 1999) and has been shown to be harmful to fish, mammals, and birds through skin contact, ingestion, and inhalation (Driscoll et al 2004). Tissue samples from the affected birds showed evidence of toxic levels of microcystin. Additionally, over the last 10 years, isolated cases of young great blue herons and black-crowned night herons with steatitis have been presented to Tufts Wildlife Clinic and to rehabilitators in the northeastern US, but no largescale mortalities have been reported.

In August and October of 2008, over 70 egrets and herons also were found sick or dead in Japan (Neagari et al 2011). Weakness, lethargy, and inability to fly were reported prior to death, and significant amounts of firm subcutaneous and body cavity fat composed of necrotic adipose tissues and low levels of vitamin E were reported postmortem (Neagari et al 2011). While the reservoir where the birds were retrieved was found to exhibit high levels of cyanobacteria concurrent with the steatitis outbreak, no microcystin was detected in the reservoir water or from the livers of the egrets (Neagari et al 2011). However, the birds were observed feeding on Japanese anchovies from a nearby fish farm rather than feeding at the reservoir. Because certain types of farmed fish can carry a wide range of contaminants and toxins (Hastein et al 2006), further investigation into this observation may be of interest.

Finally, it has been suggested that steatitis may be to blame for a large number of dead and sick herons observed in 2007 at Massinger Dam, Mozambique (Myburgh 2009). While no necropsies were performed to conclusively diagnose steatitis in these birds, steatitis has been observed in crocodile and fish populations in the region, in concurrence with an observed decrease in heron populations, and in the presence of aquatic pollution and cyanobacteria (Myburgh 2009; Huchzermeyer et al 2011).

While the link between pollutants, cyanobacteria, and steatitis in birds is not well understood, it is known that vitamin $\mathrm{E}$ plays a role in protection from liver toxicity in mice (Gehringer et al 2003), rats (Sokol et al 1996), and tilapia (Prieto et al 2009), and that antioxidant depletion and subsequent lipid peroxidation in bivalves can be utilized as biomarkers for toxicity in contaminated aquatic ecosystems (Cossu et al 1997). It is plausible that factors such as pollution and microcystin deplete vitamin E stores, predisposing piscivorous birds to an increased risk of steatitis.

\section{Discussion}

To date, nearly all cases of steatitis in piscivores in the US have been reported from marine coastal areas, but to the authors' knowledge, none have been reported from inland lakes and rivers. It is impossible to know how many steatitis occurrences remain undocumented, as recognition and reporting of the disease may be low. As with many wildlife issues, wildlife rehabilitators represent an important resource for detection and documentation of steatitis in herons and other species. Although many rehabilitators do not have the resources to make definitive laboratory diagnoses, the clinical signs are fairly distinctive and a presumptive diagnosis can be made by anyone familiar with heron physical examinations.

Rehabilitators can recognize if the bird they have received may have steatitis by being aware of several factors. Most often steatitis cases are the young of the year and present as 'down and weak.' On physical exam, these birds are usually of good body weight, but when the abdomen and area over the caudal keel of the sternum are palpated, the abdomen appears swollen, firm, and 'lumpy-bumpy.' By wetting the ventral feathers with alcohol or soapy water, lumpy, yellowish 
masses are usually apparent under the skin. Please note there are other conditions that can cause lumpy, swollen abdomens, including tumors and parasitic visceral larval migrans. If radiographs (x-rays) are available, the abdominal area often appears very dense, much whiter than expected.

The authors strongly encourage rehabilitators and biologists who handle waterbirds to look for this condition, document it via photographs and written records, work with their local veterinarians to preserve clinical samples and tissues for histopathology, and notify state and federal agencies of the findings. Only in this way are we able to document the extent of the problem, determine if (and how) it is spreading, and establish what may be the causes of steatitis in wild fish-eating birds.

\section{ACKNOWLEDGEMENT}

Our thanks to Kevin Anderson, Game Warden Investigator for the Maine Department of Inland Fisheries and Wildlife, and to Marc Payne and Diane Winn of Avian Haven in Freedom, ME for their efforts ensuring this loon was recovered and preserved for postmortem examination.

This paper is a publication from the Tufts Wildlife Clinic and Center for Conservation Medicine.

\section{LITERATURE CITED}

Begg, G. S., D. W. Bruno, and A. H. McVicar. 2000. The Histopathology and Ultrastructure of Steatitis Affecting Common Dab, Limanda limanda. Diseases of Aquatic Organisms. 41(2): 123-133.

Brooks, H. V., C. G. Rammell, J. J. L. Hoogenboom, and D. E. S. Taylor. 1985. Observations on an Outbreak of Nutritional Steatitis (yellow fat disease) in Fitch (Mustella putorius furo). New Zealand Veterinary Journal. 33(9): 141-145.

Brown, J. 2011. Metal Concentrations and Lipid Peroxidation in Mozambique Tilapia (Oreochromis mossambicus) in Loskop Dam. c2012. Available from: <http://www.orf.co.za/chamber\%20 databases/orf/Com_DocMan.nsf/0/39C0E759 CF1EC93B4225788F004225D2/\$File/Jackie_ ORF_6May2011.pdf>.

Campos, A. and V. Vasconcelos. 2010. Molecular Mechanisms of Microcystin Toxicity in Animal Cells. International Journal of Molecular Sciences. 11(1): 268-287.

Coll, M., S. Libralato, S. Tudela, I. Palomera, and F. Pranovi. 2008. Ecosystem Overfishing in the Ocean. PLoS One. 3(12): e3881.
Cossu, C., A. Doyotte, M. C. Jacquin, M. Babut, A. Exinger, and P. Vasseur. 1997. Glutathione Reductase, Selenium-dependent Glutathione Peroxidase, Glutathione Levels, and Lipid Peroxidation in Freshwater Bivalves, Unio tumidus, as Biomarkers of Aquatic Contamination in Field Studies. Ecotoxicology and Environmental Safety. 38(2): 122-131.

Cury, P. M., I. L. Boyd, S. Bonhommeau, T. AnkerNilssen, R. J. M. Crawford, R. W. Furness, J. A. Mills, E. J. Murphy, H. Osterblom, M. Paleczny, J. F. Piatt, J. P. Roux, L. Shannon, and W. J. Sydeman. 2011. Global Seabird Response to Forage Fish Depletion-One Third for the Birds. Science. 334(6063): 1703-1706.

Danse, L. H., and W. A. Steenbergen-Botterweg. 1974. Enzyme Histochemical Studies of Adipose Tissue in Porcine Yellow Fat Disease. Veterinary Pathology. 11: 465-476.

Dierenfeld, E. S. 1989. Vitamin E Deficiency in Zoo Reptiles, Birds, and Ungulates. Journal of Zoo and Wildlife Medicine. 20(1): 3-11.

Driscoll, C. P., E. A. Miller, and P. M. McGowan. 2004. A Case Study: Steatitis in Great Blue Herons in Maryland. Proceedings of the 76th Northeastern Conference of Avian Diseases, State College, PA.

Dunning, J. B. 2008. CRC Handbook of Avian Body Masses, 2nd edition. CRC Press: Boca Raton, FL. p. 13.

Fabrini, F., P. Anfray, P. Viacaba, M. Gregori, and F. Abramo. 2005. Feline Cutaneous and Visceral Necrotizing Panniculitis and Steatitis Associated with a Pancreatic Tumour. Veterinary Dermatology. 16(6): 413-419.

Gehringer, M. M., S. Govender, M. Shah, and T. G. Downing. 2003. An Investigation of the Role of Vitamin E in the Protection of Mice Against Microcystin Toxicity. Environmental Toxicology. 18(2): 142-148.

Geraci, J. R., and D. J. St. Aubin. 1980. Nutritional Disorders of Captive Fish-eating Animals. Pp. 41-49 in The Comparative Pathology of Zoo Animals, (R. J. Montali and G. Migaki, editors). Smithsonian Institution Press: Washington, DC.

Hastein, T., B. Hjeltnes, A. Lillehaug, J. U. Skare, M. Berntssen, and A. K. Lundebye. 2006. Food Safety Hazards that Occur During the Production Stage: Challenges for Fish Farming and the Fishing Industry. Scientific and Technical Review of the Office International des Epizooties. 25(2): 607-625. 
Huchzermeyer, K. D. A., D. Govendar, D. J. Pienaar, and A. R. Deacon. 2011. Steatitis in Wild Sharptooth Catfish, Clarias gariepinus (Burchell), in the Olifants and Lower Letaba Rivers in the Kruger National Park, South Africa. Journal of Fish Diseases. 34(7): 489-498.

Jaeschke, H., G. J. Gores, A. I. Cederbaum, J. A. Hinson, D. Pessayre, and J. J. Lemasters. 2002. Mechanisms of Hepatoxicity. Toxicological Sciences. 65: 166-176.

Jaeschke, H., M. R. McGill, and A. Ramachandran. 2012. Oxidant Stress, Mitochondria, and Cell Death Mechanisms in Drug-induced Liver Injury: Lessons Learned from Acetaminophen Hepatotoxicity. Drug Metabolism Reviews. 44(1): 88-106.

Jennings, S., and M. J. Kaiser. 1998. The Effect of Fishing on Marine Ecosystems. Advances in Marine Biology. 34: 201-352.

Juan-Salles, C., N. Prats, A. Resendes, M. Domingo, D. Hilton, J. M. Ruiz, M. M. Garner, X. Valls, and A. J. Marco. 2003. Anemia, Myopathy, and Pansteatitis in Vitamin E-deficient Captive Marmosets (Callithrix spp.). Veterinary Pathology. 40(5): 540-547.

Kabak, Y. B., T. Guvenc, O. Kul, A. Deniz, and M. Y. Gulbahar. 2011. Systemic Toxoplasmosis in a Kangaroo. Veterinary Journal of Ankara University. 58: 209-212.

Kahn, C. M. (editor) 2005. The Merck Veterinary Manual, 9th edition. Merck \& Co: Whitehouse Station, NJ.

Kayden, H. J., and M. G. Traber. 1993. Absorption, Lipoprotein Transport, and Regulation of Plasma Concentrations of Vitamin E in Humans. Journal of Lipid Research. 34: 343-358.

Kirby, P. S. 1981. Steatitis in Fattening Pigs. Veterinary Record. 109(17): 385.

Klasing, K. C. 2000. Avian Comparative Nutrition. CABI Publishing: New York, NY.

Koutinas, A. F., W. H. Miller, M. Kritsepi, and S. Lekkas. 1993. Pansteatitis (Steatitis, "Yellow Fat Disease") in the Cat: A Review Article and Report of Four Spontaneous Cases. Veterinary Dermatology. 3(3): 101-106.

Ladds, P. W., H. Mangunwirjo, D. Sebayang, and P. W. Daniels. 1995. Diseases in Young Farmed Crocodiles in Irian Jaya. Veterinary Record. 136(5): 121-124.

Larsen, R. E., C. Buergelt, P. T. Cardeilhac, and E. R. Jacobson. 1983. Steatitis and Fat Necrosis in Captive Alligators. Journal of the American Veterinary Medical Association. 183(11): 1202-1204.
Li, G., A. J. Sinclair, and D. Li. 2011. Comparison of Lipid Content and Fatty Acid Composition in the Edible Meat of Wild and Cultured Freshwater and Marine Fish and Shrimps from China. Journal of Agricultural and Food Chemistry. 59(5): 18711881.

Manawatthana, S. and C. Kasorndorkbua. 2005. Steatitis and Vitamin E Deficiency in Captive Olive Ridley Turtles (Lepidochelys olivacea). Proceedings of the 2 nd International Symposium on SEASTAR2000 and Asian Bio-logging Science. Pp. 85-87.

Menzies-Gow, N. J., J. C. Patterson-Kane, and C. M. McGowan. 2002. Chronic Nodular Panniculitis in a Three-year-old Mare. Veterinary Record. 151(14): 416-419.

Myburgh, J., and A. Botha. 2009. Decline in Herons along the Lower Olifants River-Could Pansteatitis be a Contributing Factor? VetNuus. 3: 20-23. Available from: <http://capebirdclub.org.za/cbc/ pdf/Pansteatitis.pdf $>$.

Neagari, Y., S. Arii, M. Udagawa, M. Onuma, Y. Odaya, T. Kawasaki, M. Tenpaku, H. Hayama, K. Harada, M. Mizukami, and K. Murata. 2011. Steatitis in Egrets and Herons from Japan. Journal of Wildlife Diseases. 47(1): 49-55.

Nichols, D. K., V. L. Campbell, R.J. Montali, 1986. Pansteatitis in Great Blue Herons. Journal of the American Veterinary Medical Association. 189(9): 1110-1112.

Niza, M. M., C. L. Vilela, and L. M. Ferreira. 2003. Feline Pansteatitis Revisited: Hazards of Unbalanced Home-made Diets. Journal of Feline Medicine and Surgery. 5(5): 271-277.

Ohno, Y., A. Le Pavoux, H. Saeki, A. Asahina, and K. Tamaki. 2003. A Case of Subcutaneous Nodular Fat Necrosis with Lipase-secreting Acinar Cell Carcinoma. International Journal of Dermatology. 42(5): 384.

Outtas, O., M. Barthet, J. De Troyer, F. Franck, and S. Garcia. 2004. Pancreatic Panniculitis with Intraductal Carcinoid Tumour of the Pancreas Divisum. Annales de Dermatologie et de Venercologie. 131(5): 466-469.

Platter-Rieger, M. F., A. Fairbrother, and M. Faulkner. 1996. Heron Steatitis in Southern California. Pacific Seabirds. 23(1): 48.

Pollock, C. G., J. M. Sleeman, C. D. Houle, and E. C. Ramsay. 1999. Vitamin E Deficiency and Pansteatitis in Juvenile Boat-billed Herons (Cochlearius cochlearius). Journal of Zoo and Wildlife Medicine. 30(2): 297-300. 
Potts, D. T., M. T. Maas, and N. M. Iseman. 1975. Syndrome of Pancreatic Disease, Subcutaneous Fat Necrosis and Polyserositis: A Case Report and Review of the Literature. American Journal of Medicine. 58(3): 417-423.

Prieto A. I., A. Jos, S. Pichardo, I. Moreno, M. A. de Sotomayor, R. Moyano, A. Bianco, and A. M. Camean. 2009. Time-dependent Protective Efficacy of Trolox (vitamin E analog) Against Microcystin-induced Toxicity in Tilapia (Oreochromis niloticus). Environmental Toxicology. 24(6): 563-579.

Rattner, B. A., G. H. Olsen, P. C. McGowan, B. K. Ackerson, and M. A. McKernan. 2006. Harmful Algal Blooms and Bird Die-offs in Chesapeake Bay: A Potential Link? Chesapeake Marshlands National Wildlife Refuge Complex 3rd Annual Science Meeting. March 8, 2006. Cambridge, Maryland. Available from: <http://www.pwrc.usgs. gov/health/rattner/rattner_blackwaternwr.cfm>.

Sokol, R. J., J. M. McKim, M. C. Goff, S. Z. Ruyle, M. W. Devereaux, D. Han, L. Packer, and G. Everson. 1998. Vitamin E Reduces Oxidant Injury to Mitochondria and the Hepatotoxicity of Taurochenodeoxycholic Acid in the Rat. Gastroenterology. 114(1): 164-174.

Sullivan, J. B., and G. R. Krieger. 2001. Clinical Environmental Health and Toxic Exposures, 2nd edition. Lippincott, Williams \& Wilkins: Philadelphia, PA.

Surai, P. F., G. R. Bortolotti, A. L. Fidgett, J. D. Blount, and B. K. Speake. 2001. Effects of Piscivory on the Fatty Acid Profiles and Antioxidants of Avian Yolk: Studies on Eggs of the Gannet, Skua, Pelican and Cormorant. Journal of Zoology. 255: 305-312.

Tocidlowski, M. E., T. E Cornish, M. R. Loomis, and M. K. Stoskopf. 1997. Mortality in Captive Wild-caught Horned Puffin Chicks (Fratercula corniculata). Journal of Zoo and Wildlife Medicine. 28(3): 298-306.

Traber, M. G. 2005. Vitamin E. Chapter 21: 397-409. Modern Nutrition in Health and Disease. (M. Shils, M. Shike, A. Ross, B. Caballero, and R. Cousins, editors). Lippincott, Williams \& Wilkins: Philadelphia, PA.

Van Vleet, J. F. 1982. Amounts of Twelve Elements Required to Induce Seleniumvitamin E Deficiency in Ducklings. American Journal of Veterinary Research. 43(5): 851-857.
Walther, G., E. Post, P. Convey, A. Menzel, C. Parmesan, T. J. C. Beebee, J. Fromentin, O. Hoegh-Guldberg, and F. Bairlein. 2002. Ecological Responses to Recent Climate Change. Nature. 416: 389-395.

Webb, C. and D. Twedt. 2008. Oxidative Stress and Liver Disease. Veterinary Clinics of North America: Small Animal Practice. 38(1): 125-135.

Wong, E., I. Mikaelian, M. Desnoyers, and G. Fitzgerald. 1999. Pansteatitis in a Free-ranging Red-tailed Hawk (Buteo jamaicensis). Journal of Zoo and Wildlife Medicine. 30(4): 584-586. (NखR

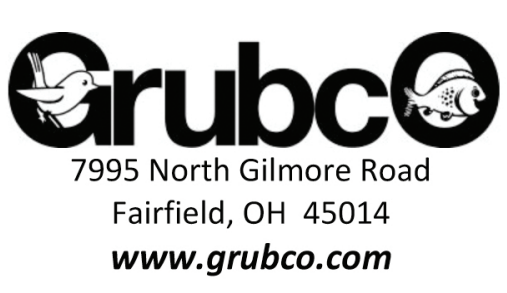

Phone orders please call 800-222-3563. We accept Visa, MasterCard, and Discover.

Wildlife rehabilitators receive a $5 \%$ discount!

Mealworms - Mini, Small,Medium, or Large.

Mighty Mealys ${ }^{\circledR}$ - Twice the size of our large mealworms. These oversized mealworms are perfect for larger animals.

Crickets -PH, 1/4", 1/2", $3 / 4 "$, and 1".
Waxworms - Rich in protein, moisture, and fat.

Superworms - These fast moving larvae are great for feeding reptiles.

Fly Larvae - These larvae are raised in a vitamin and protein rich mixture. 